\title{
VIBRATION CONTROL OF OFFSHORE WIND TURBINE TOWERS
}

\author{
ANDREAS E. KAMPITSIS ${ }^{1}$ \\ ${ }^{1}$ National Technical University of Athens (NTUA) \\ Zografou Campus,GR-157 80 Athens, Greece \\ cvakamb@gmail.com
}

Key words: Offshore Wind Turbine, Monopile,Vibration Control, Vibration Mitigation, Nonlinear FEM

\begin{abstract}
In this study, the dynamic response of a Offshore Wind Turbine (OWT) tower under wind loading is investigated adopting the vibration absorption concepts. Application of vibration control systems (VCS) to OWT towers has the potential to significantly improve the dynamics of the tower and the nacelle, increasing its reliability. The first vibration mitigation approach is the classical tuned mass damped (TMD) and it is used as benchmark. In the TMD approach an additional mass is installed inside the nacelle at the top of the OWT tower. Usually, a large additional mass is required to achieve significant effective damping, which may lead to undesirable second order effects and ultimately increase the tower displacement. In the second approach, a passive vibration absorption concept is implemented, namely the Extended KDamper (EKD). The KDamper device is a special mechanical configuration consisting of an additional mass, an artificial damper and both positive and negative stiffness elements. The OWT is subjected to extreme environmental loading such as the wind and sea waves. These OWT loadings, are usually calculated based on stochastic interpolation of meteorological data or by artificial time-histories. In this study, the Blade Element Momentum (BEM) theory is taken into consideration in order to produce the wind load time histories. The improvement on the dynamic response of the OWT tower using vibration control systems is illustrated. Moreover, this research shown that the EKD presents a significant increase of the damping ratio with a minimal value of added mass at the top of the tower.
\end{abstract}

\section{INTRODUCTION}

According to the Climate Change Conference, held in Paris 2015 (COP21), the European Union (EU) is committed to reduce $\mathrm{CO}_{2}$ emissions by 2050 by $80 \%$ compared to 1990 levels. This requires drastic decarbonisation of the energy sector. To this end, Renewable Energy Sources (RES) play a key role. The EU is planning to achieve electric energy production from RES up to $97 \%$ of the total energy demand by 2050. According to the International Energy Agency (IEA) estimates, Wind and Solar Energy represent the most promising renewables and will soon be the cheapest sources of energy, achieving worldwide $40 \%$ penetration to the electric network by 2040 [1].

The installed Wind Turbines (WT) energy potential is currently estimated at $539 \mathrm{GW}$, according to the World Wind Energy Agency (WWEA) [2]. An important part of the WT network is the offshore wind turbines (OWT). OWT are expected to increase significantly as European coasts and seas (including Greek islands) offer a large wind energy potential. The WWEA predicts that offshore wind farms of $150 \mathrm{GW}$ will operate in the EU by 2030 , contributing $14 \%$ of the EU's total electricity consumption. The energy potential multiplies when the wind energy is combined with the energy of the sea Waves kinetic 
energy. It is estimated that the possible power generated by the waves is $2 \mathrm{TW}$, equal to the world's generated electricity [3]. Only the region of the Mediterranean [4] is expected to produce renewable energy to cover $50 \%$ of the current electricity consumption in the EU. Thus, EU has launched the Blue Growth program. That is the long-term strategy to support sustainable growth in the marine and maritime sectors.

However, the above predictions are very ambitious. It is noted, that in 2018 the annual rate of WT installation reached the lowest rate (10.8\%) since the start of their industrial growth. Moreover, in recent years, several failures have been recorded in existing WT. It is estimated that the structural failure (tower, foundation) of the installed WT amounts up to $10 \%$ [5], significantly reducing their contribution to the energy network. The high demand for wind and wave energy, generates several practical challenges that prevent the achievement of the energy goals. These challenges stem mainly from the following factors:

- The large construction and foundation costs of the WT (25\%-40\% of the total cost). For offshore, the cost exponentially increases as the depth of the sea becomes greater.

- High cost of replacement/repair of the tower and foundation. It is noted that this cost is the highest one in WT industry and it is two times higher than the next in line which, is the electric generator. WT collapse due to earthquake excitations. Seismic events cause structural failures due to high dynamic stress loading exciding structural strength.

- WT collapses due to wind or/and wave loading. This continuous and cyclic loading causes failure due to structural fatigue.
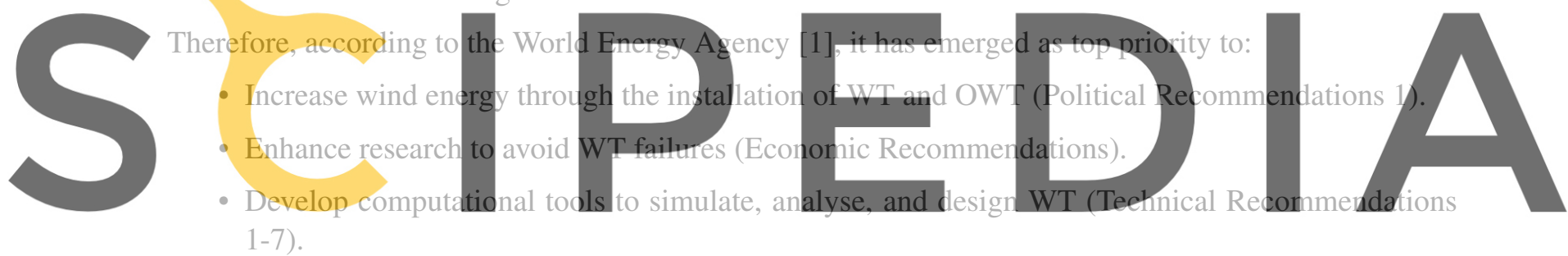

$1-7)$

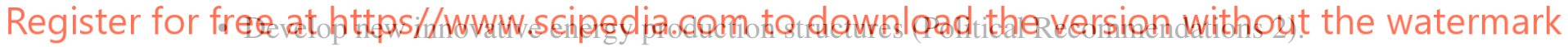

Towards facing these challenges an innovative OWT vibration control system (VCS) that protects the OWT structure from all external loading is examined.

Extensive research has been conducted to investigate the vibration mitigation of WT towers by using various vibration control systems (VCS) [6]. VCS can be classified as passive [7-13], active [14], hybrid $[15,16]$, and semi-active control [17-21]. Passive VCS are the most commonly used in engineering practice [22-24] since they are simple to model, easy to implement and reliable to perform. From the numerous passive VCS, the Tuned Mass Damper (TMD) has received significant attention in the WT vibration mitigation literature $[7,9,10]$. The principle of the TMD is the degradation of the dynamic response of the structure through the transfer of energy to an additional mass. That mass along with a positive stiffness element and an artificial damper are placed at the top of the WT tower.

Variations of the TMD have been proposed in order to address the inherent nature of the OWTs. Lackner and Rotea [9] proposed the installation of two independent TMDs located in the nacelle, in order to capture both the fore-aft and the side-side modes. Stewart and Lackner [10] presented the beneficial dynamics of an OWT with TMD when significant wind-wave misalignment is presented, while Zuo 
et al [25] proposed using multiple TMDs at certain locations along the tower in order to control the vibrations of OWT tower under the combined wind, sea wave and earthquake excitation. In almost all the aforementioned studies, the vibration control device is located in the nacelle at the top of of the tower. However, in practice the installation of any CVS in the nacelle is challenging due to the limited available space.

An indirect approach to increase the inertia effect of the additional mass of the TMD, without increasing directly the mass itself, is the KDamper concept [26]. The KDamper is essentially an extension of the traditional TMD, by introducing an appropriate negative stiffness (NS) element to the the oscillating mass of the TMD. The amplitude of the inertia force of the additional mass and the amplitude of the NS force are exactly in phase, due to the negative value of the implemented stiffness element [26,27]. Although the KDamper oscillator incorporates a NS element, it is designed to be statically and dynamically stable. Once such a system is designed properly, it is shown to exhibit extraordinary damping properties, finding numerous applications in seismic isolation of bridges [28,29], vibration absorption of WT towers [30$32]$, and implementation in the bases of structures as a stiff absorption base $[27,33,34]$.

In this study, the dynamic response of a Offshore Wind Turbine (OWT) tower under wind loading is investigated adopting the vibration absorption concepts. The novel aspect of this study are summarized as following:

1. The dynamic response of an offshore wind turbine tower founded on a monopile is studied implementing geometrically non-linear (second order) FE model, while the monopile is embedded in a layered Winkler type soil profile represented by a Kelvin-Voigt element.
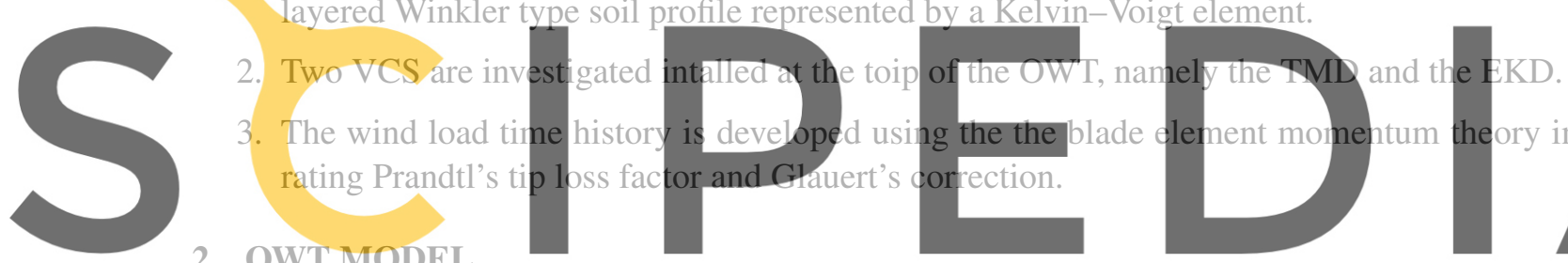

2 OWT MODEL

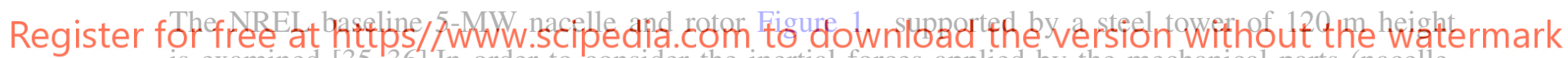
is examined $[35,36]$. In order to consider the inertial forces applied by the mechanical parts (nacelle, rotor, and blades) an additional concentrated mass $m_{o p}$ is added at the top of the tower [36]. The WT is founded on a monopile embedded in a layered Winkler type soil profile represented by a Kelvin-Voigt element. The transient nonlinear dynamic response analysis of the tower-pile system is investigated through a Beam of Variable Cross Section over a Beam on Winkler Foundation formulation accounting for both kinematic and inertia interaction. The geometrically nonlinear equation of motion of the OWT is obtained as follows:

$$
\left[\begin{array}{cc}
M_{t} & \mathbf{0} \\
\mathbf{0} & M_{p}
\end{array}\right]\left\{\begin{array}{c}
\ddot{d}_{t} \\
\ddot{d}_{p}
\end{array}\right\}+\left[\begin{array}{cc}
C_{t} & \mathbf{0} \\
\mathbf{0} & C_{p}
\end{array}\right]\left\{\begin{array}{l}
\dot{d}_{t} \\
\dot{d}_{p}
\end{array}\right\}+\left[\begin{array}{cc}
K_{t}(d) & K_{t p}(d) \\
K_{p t}(d) & K_{p}(d)
\end{array}\right]\left\{\begin{array}{l}
d_{t} \\
d_{p}
\end{array}\right\}=\left\{\begin{array}{l}
P_{t}(d) \\
P_{p}(d)
\end{array}\right\}
$$

where $(\dot{-})$ denotes differentiation with respect to the time $t$. Moreover, $\left[M_{t}\right],\left[M_{p}\right],\left[C_{t}\right]$ and $\left[C_{p}\right]$ are the mass and damping matrices of the OWT tower and monopile, respectively. $\left[K_{t}\right],\left[K_{p}\right]$ and $\left[P_{t}\right],\left[P_{p}\right]$ are the nonlinear stiffness matrices and force vectors containing the geometrically nonlinear terms, while $\left\{d_{t}, d_{p}\right\}^{T}$ denotes the vector of unknown nodal displacements. The key properties of the OWT steel tower are listed in Table 1. 


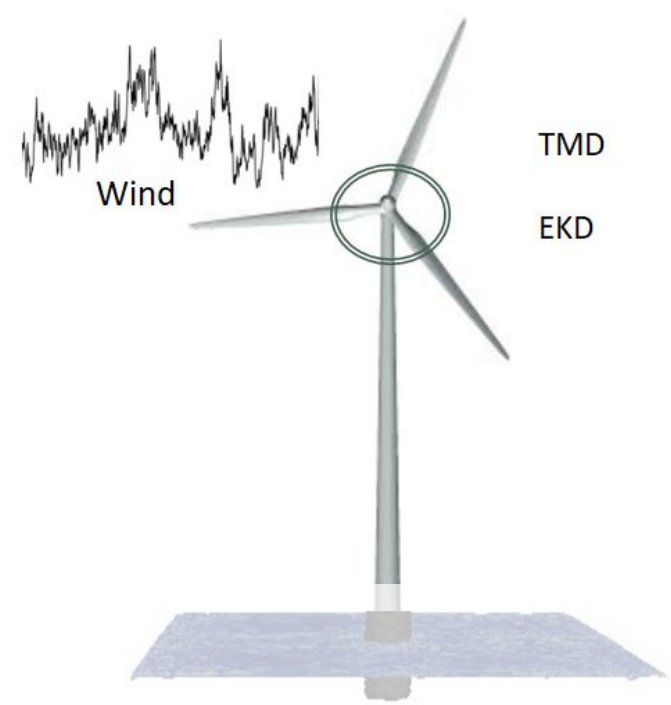

Figure 1: Offshore wind turbine tower on monopile foundation.

The first vibration mitigation approach is the classical TMD and it is used as benchmark since it is the most well studied in the literature. In the TMD approach an additional mass $m_{D}$ is installed inside the

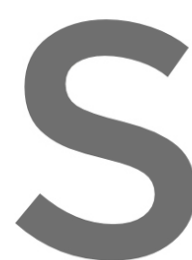
nacelle at the top of the OWT tower. The mass is attached nsing a linear damper $c_{D}$. Alternatively, oscillating mass connected to the negative stiffness (NS) nacelle with a positive stifin related matrices of Equation 1 are modified respectivly.

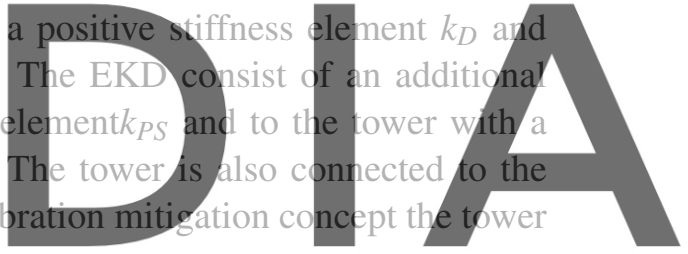

Register for free at https//www.scipedia.com to download the version without the watermark Table 1: Key properties of NREL baseline 5MW offshore wind turbine.

\begin{tabular}{llll} 
Property & Value & & \\
\hline Rating & $5 M W$ & Top thickness & $25 \mathrm{~m}$ \\
Rotor diameter & $126 \mathrm{~m}$ & Rated rotor & $12.1 \mathrm{rpm}$ \\
Hub diameter & $3 \mathrm{~m}$ & Nacelle mass & $240 \mathrm{tn}$ \\
Base diameter & $8.43 \mathrm{~m}$ & Rotor mass & $110 \mathrm{tn}$ \\
Base thickness & $48 \mathrm{~mm}$ & Young's modulus & $210 \mathrm{GPa}$ \\
Top diameter & $3.87 \mathrm{~m}$ & Steel density & $8.5 \mathrm{tn} / \mathrm{m}^{3}$ \\
Tower damping & $2 \%$ & Blade damping & $0.48 \%$ \\
\hline
\end{tabular}

\section{DESIGN OF THE VCS}

The design performance of most VCS strongly dependents on the tuned frequency ratio and damping ratio. Over the years, numerous techniques have been proposed [25,37-42] for the optimization of the key TMD or MTMD parameters. However, the complexity of the EKD configuration [33] renders the 
conventional min-max (Hinf) approaches [43] ineffective, thus a constrained optimization approach is followed [26]. As for the the negative stiffness is primarily achieved by special mechanical designs involving conventional positive stiffness prestressed elastic mechanical elements such as post-buckled beams, plates, shells, and precompressed springs $[44,45]$. In the EKD configuration, the negative stiffness element is materialized via a precompressed springs mechanism. The implementation of such configuration is simple to design and construct while it also provides very good control of the negative stiffness influence on the VCS performance $[26,46]$.

\section{WIND LOAD}

The loading due to the wind is taken into account as follows, the OWT tower is considered to be subjected to the horizontal force $\bar{F}_{N}$ due to the wind at its top, as presented in [36]. The horizontal force $\bar{F}_{N}(r, t)$ acting as a position $r$ along the wind turbine blade can be obtained by the following relation [47].

$$
\bar{F}_{N}(r, t)=\frac{1}{2} \rho_{a i r} C_{N}(r) c_{b l}(r) \bar{V}^{2}(t)
$$

where $C_{N}(r)$ is the coefficient computed by the corresponding lift $C_{L}(r)$ and $\operatorname{drag} C_{D}(r)$ coefficients and $\rho_{\text {air }}=1.2 \times 10^{-3} \mathrm{tn} / \mathrm{m}^{3}$. The values of the latter coefficients depend on the airfoil characteristics of the blades and their distribution with respect to the angle of attack of the wind velocity $\bar{V}(t)$ vector passing through the blade profile can be retrieved from. It is noted that the velocity vector is assumed to have a uniform spatial distribution over the actuator disc. $c_{b l}(r), \beta(r)$ is the chord and the pitch angle of the

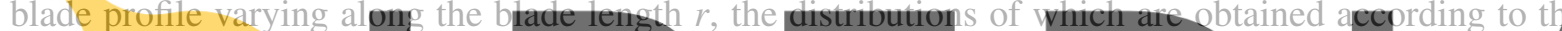
blade type employed to
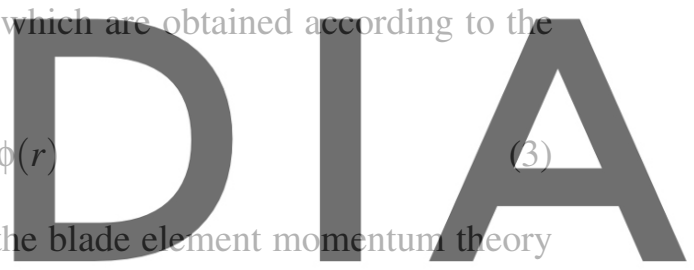

incorporating Prandtl's tip loss factor and Glauert's correction [47] is employed with an assumption of

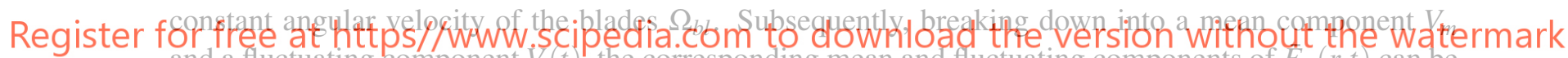
and a fluctuating component $V(t)$, the corresponding mean and fluctuating components of $F_{N}(r, t)$ can be obtained as:

$$
\begin{gathered}
F_{N m}=\frac{1}{2} \rho_{a i r} C_{N}(r) c_{b l}(r) \bar{V}_{m}^{2} \\
F_{N}(r, t)=\frac{1}{2} \rho_{a i r} C_{N}(r) c_{b l}(r)\left(2 V_{m} V(t)+V^{2}(t)\right)
\end{gathered}
$$

The mean velocity is obtained by employing a basic velocity at the altitude of $10 \mathrm{~m}, V_{b}$ and applying the corresponding regulations of EC1, Part1,4 [48], Moreover, in order to take into account, the wind velocity fluctuation at the altitude of $l_{t}$ an artificial velocity time history is generated applying the procedures presented in [49-52] assuming a value of standard deviation $\sigma$. After having established $\bar{F}_{N}(r, t)$, the total concentrated force exerted on the top of the tower can be computed as:

$$
\bar{F}_{N}(t)=3 \int_{0}^{r_{b l}} \bar{F}_{N}(r, t) d r
$$




\section{NUMERICAL RESULTS}

On the basis of the numerical procedures presented, a computer program has been written and an extensive case study has been made to investigate the efficiency and the accuracy of the developed procedure as well as to highlight the structural aspects related to the various VCSs. The design criterion of the TMD and EKD is their mass ratio, which corresponds to the additional mass added to the system. In order to verify that this approach is indeed optimum for the implementation of the TMD to a OWT tower, the maximum top displacement over the TMD tuning frequency is illustrated in Figure 2, for various values of the TMD damping ratio, and the aerodynamic load presented previously. The mass ratio of TMD is selected for the considered analysis as $5 \%$.

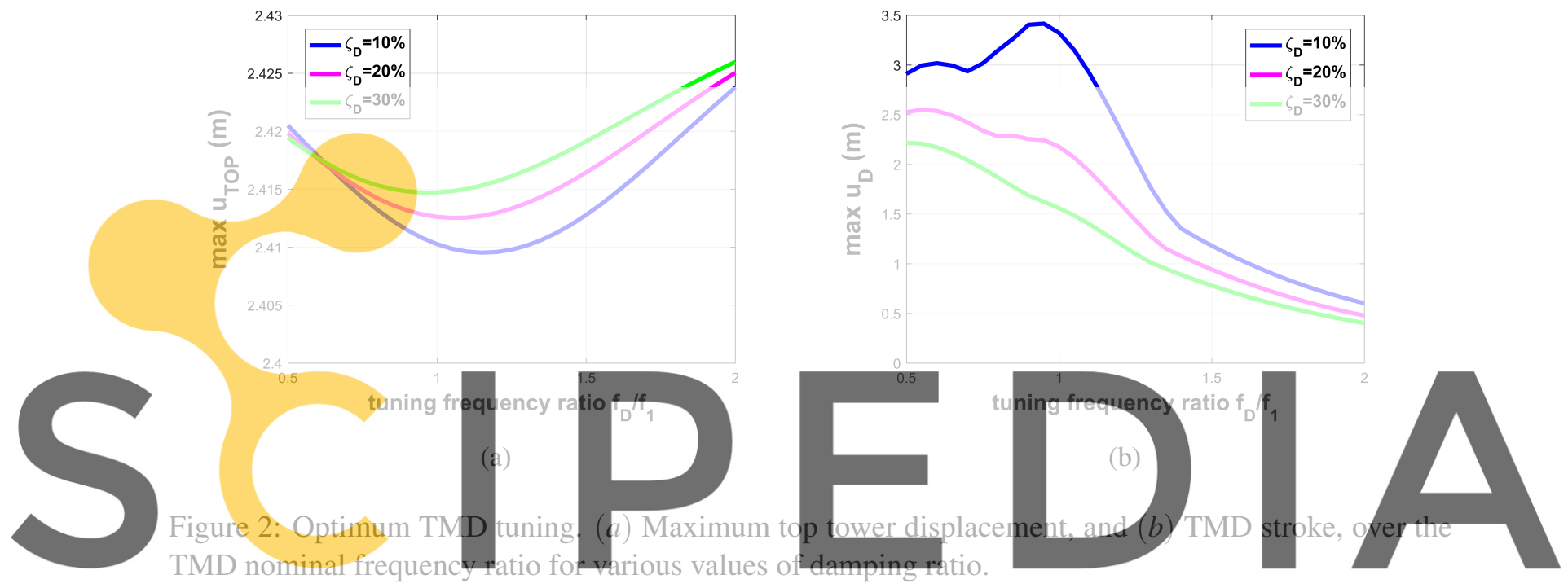

\section{Register for freeg at https/fwww.scipedia.com to download the version without the watermark}

and the EKD are illustrated in Figure 3. The EKD designs manage to greatly improve the dynamic

behavior of the OWT tower. The effective damping ratio of the WT tower increases up to $10 \%$ with the EKD system with only $0.1 \%$ additional mass. The nacelle's dynamic response variables are also improved, with the exception of the nacelle's relative velocity, where a slight increase is observed. In addition, EKD greatly reduce the NS element stroke and the relative to the top of the tower displacement of the oscillating mass of the proposed devices, making the configuration design more realistic.

\section{CONCLUSIONS}

In this paper, two dynamic vibration absorber options are examined for improving the OWT tower dynamic behavior and increasing the effective damping, i.e. the conventional TMD and the EKD. The following conclusive comments can be made:

1. The geometrically nonlinear dynamic model of the OWT tower develop herein is suitable for reallife WT applications.

2. The proposed model obtains accurate results, providing a simple and efficient tool. 


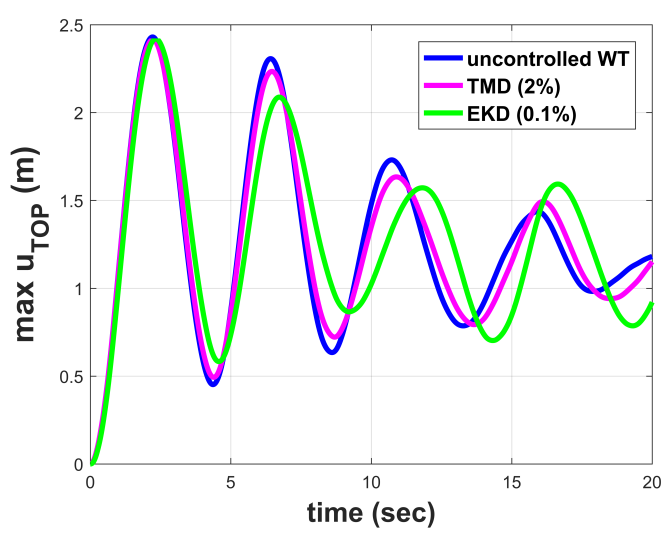

(a)

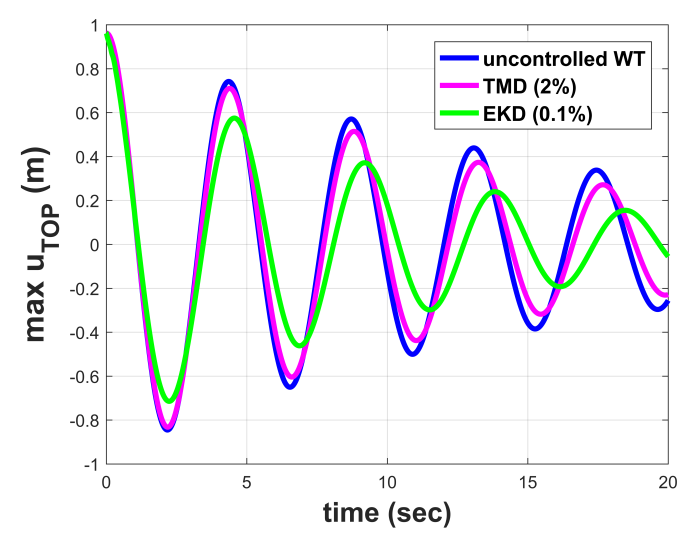

(b)

Figure 3: Dynamic responses of the controlled OWT: $(a)$ top tower displacement due to the aerodynamic load, (b) top tower displacement considering a free vibration with initial conditions.

3. The EKD provided significant increase in the effective damping of the OWT tower as compared to the TMD.

4. The KDamper-based configurations are much more effective than the conventional TMD.

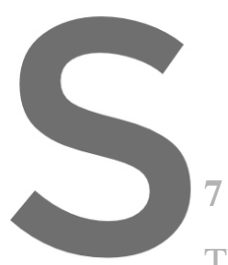

5. Monopile system leads to performance design of the

\section{ACKNOWLEDGMENTS}

This research is co-financed by
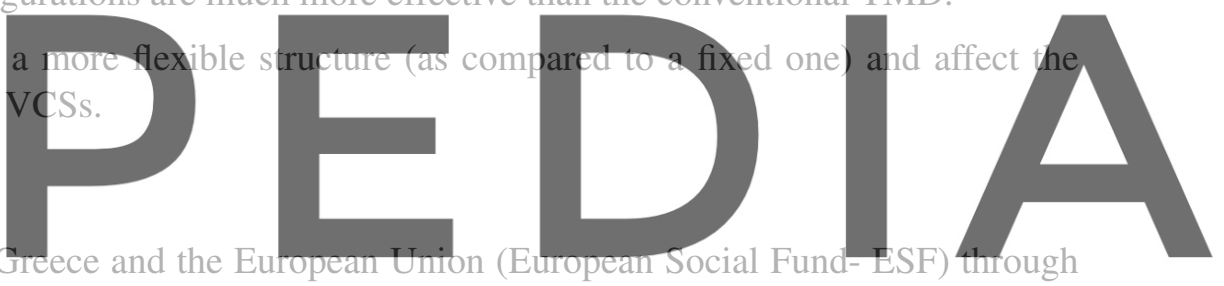

the Operational Programme "Human Resources Development, Education and Lifelong Learning" in the

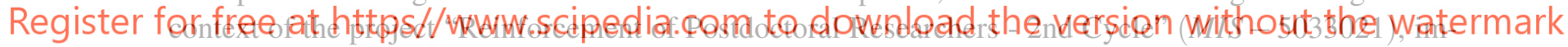

plemented by the State Scholarships Foundation (IKY).

\section{REFERENCES}

[1] IEA. World energy model. Technical report, 2020.

[2] Wind Power Capacity reaches 546 GW, 60 GW - World Wind Energy Association, 2017.

[3] Kester Gunn and Clym Stock-Williams. Quantifying the global wave power resource. Renewable Energy, 44:296-304, 2012.

[4] Francisco Huera-Huarte. Deep Water: The next step for offshore wind energy. A report by the European Wind Energy Association. 102013.

[5] Yao Li. Research and Development of the Wind Turbine Reliability. International Journal of Mechanical Engineering and Applications, 6(2):35, 2018.

[6] Mahmudur Rahman, Zhi Chao Ong, Wen Tong Chong, Sabariah Julai, and Shin Yee Khoo. Performance enhancement of wind turbine systems with vibration control: A review. Renewable and 
Sustainable Energy Reviews, 51:43-54, 2015.

[7] P. J. Murtagh, A. Ghosh, B. Basu, and B. M. Broderick. Passive control of wind turbine vibrations including blade/tower interaction and rotationally sampled turbulence. Wind Energy, 11(4):305$317,2008$.

[8] Shane Colwell and Biswajit Basu. Tuned liquid column dampers in offshore wind turbines for structural control. Engineering Structures, 31(2):358-368, feb 2009.

[9] Matthew A. Lackner and Mario A. Rotea. Passive structural control of offshore wind turbines. Wind Energy, 14(3):373-388, apr 2011.

[10] Gordon Stewart and Matthew Lackner. The impact of passive tuned mass dampers and wind-wave misalignment on offshore wind turbine loads. Engineering Structures, 73, 2014.

[11] Akwasi F. Mensah and Leonardo Dueñas-Osorio. Improved reliability of wind turbine towers with tuned liquid column dampers (tlcds). Structural Safety, 47:78-86, 2014.

[12] Jian-Bing Chen, Youkun Liu, and Xueyuan Bai. Shaking table test and numerical analysis of offshore wind turbine tower systems controlled by tlcd. Earthquake Engineering and Engineering Vibration, 14:55-75, 032015.

[13] Suzana Avila, Maura Shzu, Marcus Morais, and Zenon Prado. Numerical Modeling of the Dynamic Behavior of a Wind Turbine Tower. Advances in Vibration Engineering, 4, 2016.

[14] Zili Zhang, Søren Nielsen, F. Blaabjerg, and Dao Zhou. Dynamics and control of lateral tower

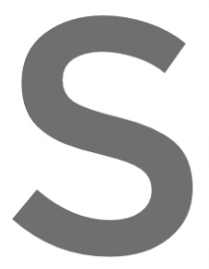
vibrations in offshore wind turbines by means of active generator torque. Energies, 7:7746-7772, 112014

15] Seshasayee Ankireddi and Henty T.Y. Yang. subject to wind loads. Journal of Structural E
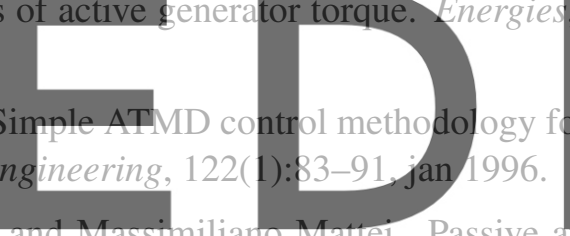

[16] Francesco Ricciardelli, A. David Pizzimenti. damper control of the response of tall buildings to wind gustiness. Engineering Structures,

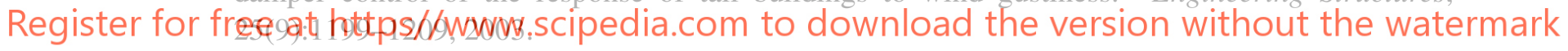

[17] G J Liao, X L Gong, C J Kang, and S H Xuan. The design of an active-adaptive tuned vibration absorber based on magnetorheological elastomer and its vibration attenuation performance. Smart Materials and Structures, 20(7):075015, jun 2011.

[18] F Weber, C Boston, and M Maślanka. An adaptive tuned mass damper based on the emulation of positive and negative stiffness with an MR damper. Smart Materials and Structures, 20(1):015012, $\operatorname{dec} 2011$.

[19] Fabio Casciati, José Rodellar, and Umut Yildirim. Active and semi-active control of structures theory and applications: A review of recent advances. Journal of Intelligent Material Systems and Structures, 23(11):1181-1195, jul 2012.

[20] M. A. Acar and C. Yilmaz. Design of an adaptive-passive dynamic vibration absorber composed of a string-mass system equipped with negative stiffness tension adjusting mechanism. Journal of Sound and Vibration, 332(2):231-245, jan 2013.

[21] F Weber. Optimal semi-active vibration absorber for harmonic excitation based on controlled semi- 
active damper. Smart Materials and Structures, 23(9):095033, aug 2014.

[22] T. T. Soong and Gary F. Dargush. Passive energy dissipation systems in structural engineering. Wiley, 1997.

[23] F. Casciati and F. Giuliano. Performance of Multi-TMD in the Towers of Suspension Bridges. Journal of Vibration and Control, 15(6):821-847, jun 2009.

[24] Sinan Melih Nigdeli and Gebrail Bekdaş. Optimum tuned mass damper design in frequency domain for structures. KSCE Journal of Civil Engineering, 21(3):912-922, mar 2017.

[25] Haoran Zuo, Kaiming Bi, and Hong Hao. Using multiple tuned mass dampers to control offshore wind turbine vibrations under multiple hazards. Engineering Structures, 141:303-315, 2017.

[26] Ioannis A. Antoniadis, Stratis A. Kanarachos, Konstantinos Gryllias, and Ioannis E. Sapountzakis. KDamping: A stiffness based vibration absorption concept. JVC/Journal of Vibration and Control, 24(3):588-606, 2018.

[27] K.A. Kapasakalis, I.A. Antoniadis, and E.J. Sapountzakis. Performance assessment of the KDamper as a seismic Absorption Base. Structural Control and Health Monitoring, 27(4), 2020.

[28] KA Kapasakalis, CHT Alamir, IA Antoniadis, and EJ Sapountzakis. Frequency Base Design of the KDamper Concept for Seismic Isolation of Bridges. In Proceedings of the 14th International Conference on Vibration Problems (ICOVP 2019), 2019.

[29] EJ Sapountzakis, KA Kapasakalis, and IA Antoniadis. Negative Stiffness Elements in Seismic Isolation of Bridges. In Proceedings of the 2nd International Conference on Natural Hazards \&

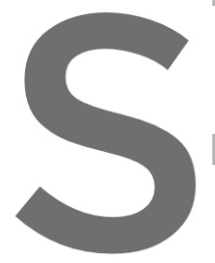
Infrastructure (IC

[30] KA Kapasakalis, H. Structures on Compliant Supports. In Proceedin Engineering (16ECEE 2018). 2018.
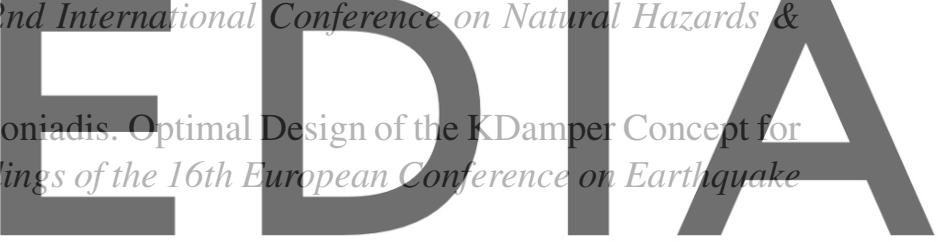

[31] K.A. Kapasakalis, E.I. Sapountzakis, and I.A. Antoniadis. Implementation of the KDamper concept

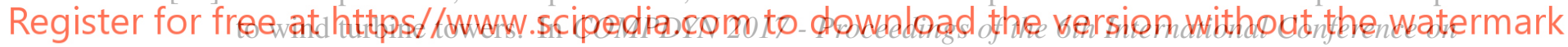
Computational Methods in Structural Dynamics and Earthquake Engineering, volume 1, 2017.

[32] K. A. Kapasakalis, P. O.N. Bollano, E. J. Sapountzakis, and I. A. Antoniadis. Comparison of alternative dynamic vibration mitigation approaches for wind turbine towers. In Proceedings of the International Conference on Structural Dynamic , EURODYN, volume 1, pages 1358-1372. European Association for Structural Dynamics, 2020.

[33] K.A. Kapasakalis, I.A. Antoniadis, and E.J. Sapountzakis. Constrained optimal design of seismic base absorbers based on an extended KDamper concept. Engineering Structures, 226, 2021.

[34] Konstantinos A. Kapasakalis, Antonios E. Alvertos, Antonios G. Mantakas, Ioannis A. Antoniadis, and Evangelos J. Sapountzakis. Advanced negative stiffness vibration absorber coupled with soilstructure interaction for seismic protection of buildings. In Proceedings of the International Conference on Structural Dynamic , EURODYN, volume 2, pages 4160-4176. European Association for Structural Dynamics, 2020.

[35] A. Quilligan, A. O'Connor, and V. Pakrashi. Fragility analysis of steel and concrete wind turbine 
towers. Engineering Structures, 36:270-282, mar 2012.

[36] E. Sapountzakis, I. Dikaros, A. Kampitsis, and A Koroneou. Nonlinear response of wind turbines under wind and seismic excitations with soil-structure interaction. Journal of Computational and Nonlinear Dynamics, 10:041007, 072015.

[37] Masato Abé and Yozo Fujino. Dynamic characterization of multiple tuned mass dampers and some design formulas. Earthquake Engineering \& Structural Dynamics, 23(8):813-835, 1994.

[38] G. B. Warburton. Optimum absorber parameters for various combinations of response and excitation parameters. Earthquake Engineering \& Structural Dynamics, 10(3):381-401, 1982.

[39] Sadek F, Mohraz B, Taylor AW, and Chung RM. A method of estimating the parameters of tuned mass dampers for seismic applications. Earthquake Engineering \& Structural Dynamics, 26(6):617-635, 1997.

[40] Chunxiang Li. Optimum multiple tuned mass dampers for structures under the ground acceleration based on ddmf and admf. Earthquake Engineering \& Structural Dynamics, 31(4):897-919, 2002.

[41] S. V. Bakre and R. S. Jangid. Optimum parameters of tuned mass damper for damped main system. Structural Control and Health Monitoring, 14(3):448-470, 2007.

[42] Nam Hoang, Yozo Fujino, and Pennung Warnitchai. Optimal tuned mass damper for seismic applications and practical design formulas. Engineering Structures, 30(3):707-715, 2008.

[43] J P Den Hartog. Mechanical Vibrations. New York, 4th ed edition, 1956.
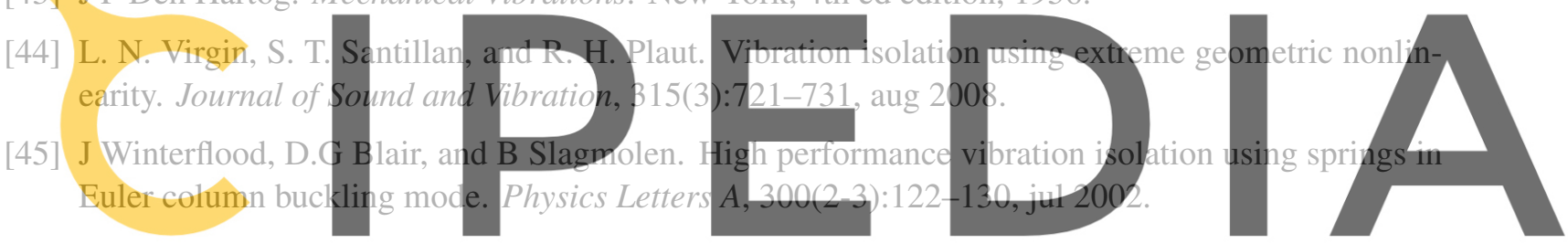

[46] A. Carrella, M. J. Brennan, and T. P. Waters. Static analysis of a passive vibration isolator with

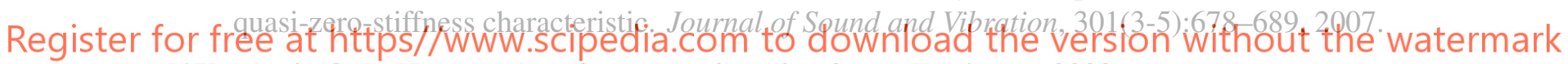

[47] Martin O. L. Hansen. Aerodynamics of wind turbines. Earthscan, 2008.

[48] EN 1991-1-4: Eurocode 1: Actions on structures - Pait 1-4: General actions - Wind actions. Technical report, 2010.

[49] Mario Di Paola. Digital simulation of wind field velocity. Journal of Wind Engineering and Industrial Aerodynamics, 74-76:91-109, 1998.

[50] Norske Veritas (Organization) and Forskningscenter Risø. Guidelines for design of wind turbines. Det Norske Veritas, Copenhagen ;[Roskilde Denmark], 2nd ed. edition, 2002.

[51] J M Jonkman. Dynamics Modeling and Loads Analysis of an Offshore Floating Wind Turbine. Technical Report No. NREL/TP-500-41958. Technical report, 2007.

[52] Konstantina Koulatsou, Francesco Petrini, Stelios Vernardos, and Charis J Gantes. Artificial Time Histories of Wind ActionsFor Structural Analysis of Wind Turbines. Technical report, 2013. 